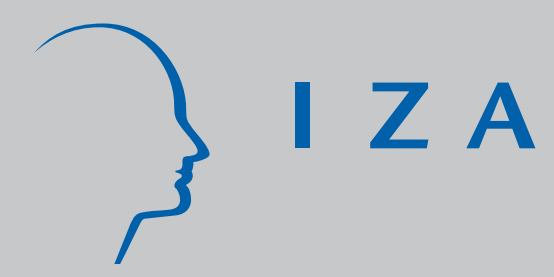

IZA DP No. 1362

Wage Differentials in the 1990s in Israel:

Endowments, Discrimination, and Selectivity

Shoshana Neuman

Ronald L. Oaxaca

October 2004 


\title{
Wage Differentials in the 1990s in Israel: Endowments, Discrimination, and Selectivity
}

\author{
Shoshana Neuman \\ Bar-llan University, \\ CEPR and IZA Bonn \\ Ronald L. Oaxaca \\ University of Arizona \\ and IZA Bonn
}

\section{Discussion Paper No. 1362 \\ October 2004}

\author{
IZA \\ P.O. Box 7240 \\ 53072 Bonn \\ Germany \\ Phone: +49-228-3894-0 \\ Fax: +49-228-3894-180 \\ Email: iza@iza.org
}

Any opinions expressed here are those of the author(s) and not those of the institute. Research disseminated by IZA may include views on policy, but the institute itself takes no institutional policy positions.

The Institute for the Study of Labor (IZA) in Bonn is a local and virtual international research center and a place of communication between science, politics and business. IZA is an independent nonprofit company supported by Deutsche Post World Net. The center is associated with the University of Bonn and offers a stimulating research environment through its research networks, research support, and visitors and doctoral programs. IZA engages in (i) original and internationally competitive research in all fields of labor economics, (ii) development of policy concepts, and (iii) dissemination of research results and concepts to the interested public.

IZA Discussion Papers often represent preliminary work and are circulated to encourage discussion. Citation of such a paper should account for its provisional character. A revised version may be available directly from the author. 
IZA Discussion Paper No. 1362

October 2004

\section{ABSTRACT}

\section{Wage Differentials in the 1990s in Israel: Endowments, Discrimination, and Selectivity}

The purpose of this paper is to investigate wage structures of professional workers in the Israeli labor market, using data from the most recent 1995 Census and correcting for selectivity at the stage of entrance into the occupation. The sample of professionals is decomposed into several subsamples: men and women and within each gender a distinction is made between Easterners (origination from Asian/African countries) and Westerners (from European/American countries of origin). Comparisons by gender and ethnicity can then be made. Characteristics (endowments) and wage structures of the four groups are presented. Wage equations include the Inverse of Mill's Ratio as a regressor to correct for selection into the professional occupations. Wage differences are then examined and decomposed into 3 components: Endowments (human capital), discrimination and selectivity. Following the methodology presented in Neuman and Oaxaca (2004), four alternative decompositions are suggested and discussed.

JEL Classification: J15, J16, J31, J44, J71

Keywords: endowments, discrimination, selectivity, gender, ethnicity, Israel

Corresponding author:

Shoshana Neuman

Department of Economics

Bar-Ilan University

52900 Ramat-Gan

Israel

Email: neumans@mail.biu.ac.il 


\section{Introduction}

Wage equations for both genders, wage differentials and segregation have been studied intensively since the 1960s. Research has been carried out on theoretical aspects, estimation methodologies, econometric issues and empirical estimation. A comprehensive review of the literature is beyond the scope of this paper. To mention but a few studies: a series of papers edited by Asplund in Pereira (1999) on gender wage equations in 15 European countries; and Blau and Kahn (2003), who investigated international differences in gender in European countries. Polachek (1975, 1976, $1979,1994)$ leads a group of economists who use human capital theories to explain gender wage differentials and segregation, and Bergmann (1974, 1986, 1996) another group emphasizing discrimination. Clearly, different explanations for the source of gender differences lead to different policies for combatting women's inferiority in the labor market. While human capital theories favor increasing investment in women's education, training and selection of occupational path, discriminative theories call for affirmative action, laws against discrimination, and the like. Rather than being competitive, these two theories are complementary. There are difference in human capital levels (mainly in experience and training) and discrimination is also prevalent (measured by different rates of return to human capital).

Blinder (1973) and Oaxaca (1973) were the first to suggest a methodology for estimating the contributions of human capital differences and of discrimination to gender (racial or ethnic) wage differentials.

Typically, one uses the separately estimated (log) wage equations for two groups of workers to decompose the difference in their (geometric) mean wages into a discrimination (unexplained) portion and a human capital (endowments or explained) portion. The simplest decomposition procedure is to adopt one of the estimated wage structures as the nondiscriminatory norm. Often researchers select the wage structure for the group of workers believed to be dominant in the labor market (at least 
relative to the comparison group). One implication of this procedure is that all of the discriminatory wage differential is ascribed to underpayment of the subordinate group rather than to overpayment of the dominant group. A more general approach to wage decompositions is found in Neumark (1988), Oaxaca and Ransom (1988), and Oaxaca and Ransom (1994). In the more general approach the nondiscriminatory wage structure is estimated from a pooled sample of the two demographic groups. This approach allows the discrimination component to be further disaggregated into overpayment (favoritism) and underpayment (pure discrimination).

Refinements in measuring labor market discrimination and endowment differences incorporate the gender and ethnic compositions of each occupation as determinants of occupational wages: Hirsch and Macpherson (1994), Hirsch and Schumacher (1992), and Macpherson and Hirsch (1995). Panel data techniques are used to control for occupational characteristics and unmeasured worker characteristics encompassing skill and tastes. In another set of studies the contribution of occupational segregation to the wage differential was estimated separately so that the difference between the wages of the groups under consideration was now decomposed into three components: the endowment component, wage discrimination, and segregation. Examples of such papers are Brown et al. (1980), Miller (1987), Reilly (1991), and Neuman and Silber (1996).

Another set of papers explores econometric issues, such as selectivity bias. Selectivity bias might be found at two stages of the employment process: at the stage of joining the employed labor force and when a specific occupation or an occupational status (e.g. union/nonunion) is chosen. Occupational selectivity bias affects wage differentials as occupations differ in average wage rates (even after controlling for workers' characteristics) and barriers to entrance of the subordinate group create another source of discrimination. In the presence of sample selection, of both types, $O L S$ estimation of the wage equations can yield biased and inconsistent estimators, 
Gronau (1974) and Heckman $(1976,1979)$. While correction for the first type is standard, correction for the second type is not usually done, and if it is performed it is not taken to the stage of decomposing wage differentials including the decomposition of the Inverse Mills Ratio. Reimers (1983) and Boymond et.al. (1994) estimate the effects of labor market discrimination, correcting for sample selection bias in a rather simplistic way. Neuman and Oaxaca (2004) show that sample selection complicates the interpretation of wage decompositions. They offer several alternative decompositions, each based on different assumptions and objectives. Section II presents a brief description of the decomposition of selectivity corrected wage equations.

Numerous empirical studies examined the behavior of the genders in the labor market, including participation, unemployment, unionization, wage structure, wage differentials, discrimination, segregation(e.g., Blau and Ferber, 1992; Jacobsen, 1994; Asplund and Pereira, 1999; Blau and Kahn, 2003). However, very little empirical research on these issues has been done using Israeli data (Neuman and Weisberg, 1998; Neuman and Oaxaca, 2003). This paper aims to contribute toward filling this gap. Also, one of the main contributions of this paper is the application of a new proposed methodology of correction for gender/ethnic selectivity at the stage of entrance into the occupation. We therefore focus on a specific occupational category. We chose to focus on professional workers assuming that it is a relatively high-status occupation where barriers to entrance might exist, and they should be accounted for (while they probably do not exist in an occupation such as laborers). The most recent Israeli Census of Population and Housing (1995) is used to examine male and female professional workers. Characteristics and wage equations are investigated in Section III, wage decompositions and selection effects in Section IV, and concluding remarks in Section V.

In order not to confuse gender and ethnic differences, gender differences are examined within each ethnic group: Westerners and Easterners. A worker is referred to 
as a Westerner if he was born in Europe, America, South Africa or Australia, or if he is Israeli-born and his father was born in one of these places. An Easterner is a worker who was born in Asia or Africa (excluding South Africa and Israel), or if he is Israeli-born and his father was born in Asia/Africa. Second generation Israelis are part of the Western group. The shares of Westerners and Easterners in the Jewish population (in 1995) are about $65 \%$ and $35 \%$. To add more insight we also consider ethnic wage differentials within each gender group.

Wages of professional, full-time, salaried workers are analyzed, including the following: Academic professionals; Associate professionals and technicians; and Managers. Reference to professional workers only results in more homogeneous groups, however there is still a diversity of occupations within the professional occupation (25 two-digit occupations).

\section{Methodology}

To determine the contributions of endowments, discrimination and selectivity in the gender wage gap, the selectivity-corrected wage equations are decomposed. There appear to be several alternatives for decomposition (Neuman and Oaxaca, 2004) and the various options are compared and discussed, including policy implications. The decomposition methodology we employ incorporates selection effects in estimating gender wage differentials in professional employment. We will briefly summarize the methodology. For a more comprehensive discussion of the selection decomposition methodology see Neuman and Oaxaca (2004).

We employ a two equation model of wage determination and occupational employment among employed workers. Let the occupational employment and wage functions for professionals be given by

$$
\begin{aligned}
& E_{i}^{*}=H_{i}^{\prime} \gamma+\varepsilon_{i}, \\
& Y_{i}=X_{i}^{\prime} \beta+u_{i},
\end{aligned}
$$


where $E_{i}^{*}$ is a latent variable associated with being employed in a professional occupation, $H_{i}^{\prime}$, is a vector of determinants of occupational employment, $Y_{i}$ is the market wage (in logs) for professionals, $X_{i}^{\prime}$ is a vector of determinants of market wages, $\gamma$ and $\beta$ are the associated parameter vectors, and $\varepsilon_{i}$ and $u_{i}$ are i.i.d error terms that are assumed to follow a bivariate normal distribution $\left(0,0, \sigma_{\varepsilon}, \sigma_{u}, \rho\right)$.

The probability of being employed in a professional occupation is given by

$$
\begin{aligned}
\operatorname{Prob}\left(E_{i}^{*}\right. & >0)=\operatorname{Prob}\left(\varepsilon_{i}>-H_{i}^{\prime} \gamma\right) \\
& =\Phi\left(H_{i}^{\prime} \gamma\right)
\end{aligned}
$$

where $\Phi(\cdot)$ is the standard normal C.D.F. (the variance of $\varepsilon$ is normalized to 1 ). Wages are observed for those for whom $E_{i}^{*}>0$, so that the expected wage of a worker observed to be employed as a professional is given by

$$
\begin{aligned}
E\left(Y_{i} \mid E_{i}^{*}>0\right) & =X_{i}^{\prime} \beta+E\left(u_{i} \mid \varepsilon_{i}>-H_{i}^{\prime} \gamma\right) \\
& =X_{i}^{\prime} \beta+\theta \lambda_{i}
\end{aligned}
$$

where $\theta=\rho \sigma_{u}, \lambda_{i}=\phi\left(H_{i}^{\prime} \gamma\right) / \Phi\left(H_{i}^{\prime} \gamma\right)$, and $\phi(\cdot)$ is the standard normal density function. The estimating equation for those employed professionals may be expressed as

$$
Y_{i} \mid L_{i}^{*}>0=X_{i}^{\prime} \beta+\theta \lambda_{i}+\text { error }
$$

We are interested in decomposing the gender wage gap among professionals in the presence of sample selectivity:

$$
\bar{Y}_{m}-\bar{Y}_{f}=\left(\bar{X}_{m}^{\prime} \widehat{\beta}_{m}+\widehat{\theta}_{m} \widehat{\lambda}_{m}\right)-\left(\bar{X}_{f}^{\prime} \widehat{\beta}_{f}+\widehat{\theta}_{f} \widehat{\lambda}_{f}\right)
$$

where the parameters of (5) are estimated by the Heckman procedure separately for males and females. It follows from (5) that correction for selectivity bias requires a 
wage decomposition of the following sort:

$$
\begin{aligned}
\bar{Y}_{m}-\bar{Y}_{f}= & \underbrace{\bar{X}_{m}^{\prime}\left(\hat{\beta}_{m}-\widehat{\beta}^{*}\right)+\bar{X}_{f}^{\prime}\left(\widehat{\beta}^{*}-\hat{\beta}_{f}\right)}_{\text {discrimination }}+\underbrace{\left(\bar{X}_{m}-\bar{X}_{f}\right) \widehat{\beta}^{*}}_{\text {endowments }} \\
& +\underbrace{\left(\widehat{\theta}_{m} \widehat{\lambda}_{m}-\widehat{\theta}_{f} \widehat{\lambda}_{f}\right)}_{\text {selectivity }}
\end{aligned}
$$

where $\widehat{\beta}^{*}$ is an estimated nondiscriminatory wage structure apart from selectivity effects. The first two terms in 6 correspond to pure favoritism toward males and pure discrimination against females, the third term is the human capital component. The last term measures the contribution of selection effects to the observed gender wage gap.

A choice has to be made as to which wage structure is to be regarded as the nondiscriminatory standard. Three possibilities that come to mind are the estimated male wage structure $\left(\widehat{\beta}^{*}=\hat{\beta}_{m}\right)$, the estimated female wage $\operatorname{structure}\left(\widehat{\beta}^{*}=\hat{\beta}_{f}\right)$, and a pooled Neumark/Oaxaca-Ransom wage structure ${ }^{1}$. Because of the familiar index number problem these choices do not imply the same estimates of discrimination and endowment effects. In particular using the estimated male wage structure as the norm assumes that all of the discrimination against women is attributable to favoritism toward men whereas using the estimated female wage structure assumes that all of the discrimination against women is pure discrimination. In terms of practical application for correcting gender salary inequities, the use of the female wage structure as the equity standard presents potential problems of implementation associated with legal restrictions and employee morale (see Oaxaca and Ransom, 2003). Consequently, we follow much of the literature and adopt the estimated male wage structure as the nondiscriminatory norm. In our case this yields the following

\footnotetext{
${ }^{1}$ If the pooled wage structure is used, the selectivity term can be expanded to $\hat{\theta}\left(\widehat{\lambda}_{m}-\widehat{\lambda}_{f}\right)+$ $\left(\widehat{\theta}_{m}-\widehat{\theta}\right) \widehat{\lambda}_{m}+\left(\widehat{\theta}-\widehat{\theta}_{m}\right) \widehat{\lambda}_{f}$, where $\widehat{\theta}$ is the estimated Inverse Mills Ratio coefficient from the pooled male-female sample.
} 
decomposition:

$$
\bar{Y}_{m}-\bar{Y}_{f}=\underbrace{\bar{X}_{f}^{\prime}\left(\widehat{\beta}_{m}-\widehat{\beta}_{f}\right)}_{\text {discrimination }}+\underbrace{\left(\bar{X}_{m}-\bar{X}_{f}\right)^{\prime} \widehat{\beta}_{m}}_{\text {endowments }}+\underbrace{\left(\widehat{\theta}_{m} \widehat{\lambda}_{m}-\widehat{\theta}_{f} \widehat{\lambda}_{f}\right)}_{\text {selectivity }}
$$

The first two terms in (7) are the familiar discrimination and human capital components. The last term measures the contribution of selection effects to the observed gender wage gap. We shall refer to (6) as Decomposition \#1. This decomposition is noncommittal regarding the role of selection effects in labor market discrimination. Consequently, Decomposition \#1 offers little in the way of policy implications beyond the elimination of wage discrimination against employed female professional workers. This is because the only term that is explicitly associated with labor market inequity is the first term that reflects gender differences in the returns to the observable characteristics. Everything else is either identified as endowments or are lumped together in the neutral sounding category of selectivity.

One approach found in the literature is to simply net out the selection effects from the observed wage gap:

$$
\left(\bar{Y}_{m}-\bar{Y}_{f}\right)-\left(\widehat{\theta}_{m} \widehat{\lambda}_{m}-\widehat{\theta}_{f} \widehat{\lambda}_{f}\right)=\bar{X}_{f}^{\prime}\left(\widehat{\beta}_{m}-\widehat{\beta}_{f}\right)+\left(\bar{X}_{m}-\bar{X}_{f}\right)^{\prime} \widehat{\beta}_{m}
$$

Examples of this approach may be found in Duncan and Leigh (1980), Reimers (1983) and Boymond et.al. (1994). While (8) is a decomposition of the selectivity corrected wage differential, it does not provide a decomposition of the observed wage differential $\bar{Y}_{m}-\bar{Y}_{f}$

To move beyond simply accounting for selection effects requires some assumptions about what constitutes inequity in selection effects. Given such assumptions the selection term in (7) can be further decomposed in several alternative ways. Accordingly, gross selection effects can be decomposed in the following manner:

$$
\widehat{\theta}_{m} \widehat{\lambda}_{m}-\widehat{\theta}_{f} \widehat{\lambda}_{f}=\widehat{\theta}_{m}\left(\widehat{\lambda}_{f}^{0}-\widehat{\lambda}_{f}\right)+\widehat{\theta}_{m}\left(\widehat{\lambda}_{m}-\widehat{\lambda}_{f}^{0}\right)+\left(\widehat{\theta}_{m}-\widehat{\theta}_{f}\right) \widehat{\lambda}_{f}
$$


where $\hat{\lambda}_{f}^{0}$ is the mean value of the Inverse Mills Ration if females faced the same selection equation into professional employment that the men face. The term $\widehat{\theta}_{m}\left(\widehat{\lambda}_{f}^{0}-\right.$ $\widehat{\lambda}_{f}$ ) measures the effects of gender differences in the parameters of the probit selectivity equation on the male/female wage differential. The effects of gender differences in the variables that determine professional employment are measured by the term $\widehat{\theta}_{m}\left(\widehat{\lambda}_{m}-\right.$ $\hat{\lambda}_{f}^{0}$ ). The effects of gender differences in the wage response to the probability of professional employment are captured by the term $\left(\widehat{\theta}_{m}-\widehat{\theta}_{f}\right) \widehat{\lambda}_{f}$. Equivalently, this last term reflects the wage gap effects of gender differences in the correlation between the selectivity equation error term and the wage equation error term as well as gender differences in wage variability. As shown in Neuman and Oaxaca (2004) this last term could be further decomposed into gender differences in $\rho$ and $\sigma_{u}$ if desired.

How should the components of (9) be allocated to discrimination and endowments? One possibility is to include the effects of gender differences in $\theta$ in the estimated endowment (human capital) effects, and to include in the discrimination component gender differences in the estimated $\gamma$ parameters from the probit selection equation for professional employment. In this case the overall wage decomposition is given by

$$
\begin{aligned}
\bar{Y}_{m}-\bar{Y}_{f}= & \underbrace{\bar{X}_{f}^{\prime}\left(\widehat{\beta}_{m}-\widehat{\beta}_{f}\right)+\widehat{\theta}_{m}\left(\widehat{\lambda}_{f}^{0}-\widehat{\lambda}_{f}\right)}_{\text {discrimination }} \\
& +\underbrace{\left(\bar{X}_{m}-\bar{X}_{f}\right)^{\prime} \widehat{\beta}_{m}+\widehat{\theta}_{m}\left(\widehat{\lambda}_{m}-\widehat{\lambda}_{f}^{0}\right)+\left(\widehat{\theta}_{m}-\widehat{\theta}_{f}\right) \widehat{\lambda}_{f}}_{\text {endowments }} .
\end{aligned}
$$

We shall refer to the decomposition defined by (10) as Decomposition \#2. Antidiscrimination policy would entail the elimination of hiring discrimination against females seeking employment as professionals in addition to the elimination of wage discrimination against already employed female professional workers.

The most encompassing view of discrimination would be to regard gender differences in the estimated $\gamma$ parameters from the probit selection equation for professional employment and gender differences in the wage effects of selectivity $(\theta)$ as 
manifestations of discrimination. Gender differences in the values of the occupation determining variables $\left(H^{\prime}\right)$ would be treated as nondiscriminatory endowment effects. These assumptions lead to the following decomposition:

$$
\begin{aligned}
\bar{Y}_{m}-\bar{Y}_{f}= & \underbrace{\bar{X}_{f}^{\prime}\left(\widehat{\beta}_{m}-\widehat{\beta}_{f}\right)+\widehat{\theta}_{m}\left(\widehat{\lambda}_{f}^{0}-\widehat{\lambda}_{f}\right)+\left(\widehat{\theta}_{m}-\widehat{\theta}_{f}\right) \widehat{\lambda}_{f}}_{\text {discrimination }} \\
& +\underbrace{\left(\bar{X}_{m}-\bar{X}_{f}\right)^{\prime} \widehat{\beta}_{m}+\widehat{\theta}_{m}\left(\widehat{\lambda}_{m}-\widehat{\lambda}_{f}^{0}\right)}_{\text {endowments }} . \\
= & \underbrace{\bar{X}_{f}^{\prime}\left(\widehat{\beta}_{m}-\widehat{\beta}_{f}\right)+\widehat{\theta}_{m} \widehat{\lambda}_{f}^{0}-\widehat{\theta}_{f} \widehat{\lambda}_{f}}_{\text {discrimination }} \\
& +\underbrace{\left(\bar{X}_{m}-\bar{X}_{f}\right)^{\prime} \widehat{\beta}_{m}+\widehat{\theta}_{m}\left(\widehat{\lambda}_{m}-\widehat{\lambda}_{f}^{0}\right)}_{\text {endowments }}
\end{aligned}
$$

We refer to the decomposition defined by (11) as Decomposition \#3. Policy implications beyond those appropriate to Decomposition \#3 are difficult to envision. The problem is how to operationalize equal returns to professional employment selectivity. Given that the $\theta$ parameters are the products of $\rho_{1}$ and $\sigma_{u_{1}}$, it is even a challenge to make the case that gender differences in the correlation between the selectivity equation error term and the wage equation error term results from labor market discrimination. It may be equally difficult to make the case that gender differences in the standard deviation of the wage equation error term are necessarily signs of labor market discrimination.

An alternative would simply be to regard gender differences in the wage effects of 
selectivity as a separate selectivity contribution:

$$
\begin{aligned}
\bar{Y}_{m}-\bar{Y}_{f}= & \underbrace{\bar{X}_{f}^{\prime}\left(\widehat{\beta}_{m}-\widehat{\beta}_{f}\right)+\widehat{\theta}_{m}\left(\widehat{\lambda}_{f}^{0}-\widehat{\lambda}_{f}\right)}_{\text {discrimination }} \\
& +\underbrace{\left(\bar{X}_{m}-\bar{X}_{f}\right)^{\prime} \widehat{\beta}_{m}+\widehat{\theta}_{m}\left(\widehat{\lambda}_{m}-\widehat{\lambda}_{f}^{0}\right)}_{\text {endowments }} \\
& +\underbrace{\left(\widehat{\theta}_{m}-\widehat{\theta}_{f}\right) \widehat{\lambda}_{f}}_{\text {selectivity }} .
\end{aligned}
$$

We refer to the decomposition defined by (12) as Decomposition \#4. For this decomposition the policy implications are the same as for decomposition \#2.

A possible objection to the Decompositions \#2, \#3, and \#4 is the interpretation of gender differences in $\gamma$ as manifestations of labor market discrimination. The parameter vector $\gamma$ presumably reflects supply side as well as demand side valuations of personal characteristics pertaining to occupational outcomes. Also, gender differences in $\gamma$ actually reflect differences in $\sigma_{\varepsilon}$ even though $\sigma_{\varepsilon}$ is not identified and is normalized to 1 for convenience. Should gender differences in $\sigma_{\varepsilon}$ be regarded as discriminatory?

\section{Women and Men in the Israeli Labor Market: Characteristics and Wage Structures}

\section{Sample characteristics: A reflection of gender and ethnic stratification ${ }^{2}$}

Our sample includes salaried workers. They work under various different labour contracts that are prevalent in the Israeli labour market. Those who are employed in the public sector, in large firms and in the more traditional industries usually have a collective bargaining contract. It should be noted that the percentage of unionized

\footnotetext{
${ }^{2}$ We excluded from our sample immigrants who have resided less than 10 years in the country in order to confine our analysis to workers who are relatively absorbed in the Israeli labor market.
} 
workers drops constantly - falling from over $80 \%$ in the beginning of the 1980 s to about $50 \%$ in 1995 (Cohen et al,2001). Other workers have individual tenured positions and a smaller share of workers have temporary contracts or are attached to employment agencies. It should be noted that work contracts have changed significantly in recent years, particularly affecting younger workers. There is a steady move away from tenured collective agreement contracts to temporary and individual contracts. The number of workers attached to employment agencies is also growing fast.

Table 1 summarizes some socio-economic characteristics of female and male workers in the two ethnic groups based on the 20\% sample of the 1995 Census of Population and Housing, conducted by the Israeli Central Bureau of Statistics (Israel, Central Bureau of Statistics, 1998). The female sample is composed of 10,074 Jewish women - one-fourth of them are of an Eastern ethnic origin and three-fourths are Westerners. The male sample is composed of 20,388 men - only $30 \%$ of them are Easterners. The lower representation of Easterners is partly a result of lower educational attainments. In our sample of full-time, full-year salaried workers - the share of women who are professionals is smaller than the share of men. ${ }^{3}$ Moreover, the distribution within the 3 categories of professionals is different for women and men: A similar percentage of women and men (39\% and 38\%, respectively) work in academic occupations. However, only $16 \%$ of women compared with $35 \%$ of men are managers. The majority of women (45\%) work as "Associate professionals and Technicians", mainly as teachers and nurses. Only $28 \%$ of professional men belong to this category. More details can be gained from an examination of the economic sector (Table 1). About $50 \%$ of women are in the sectors of 'Education' and 'Health and Welfare', while close to $50 \%$ of men are in 'Manufacturing' and in 'Real Estate, Rent and Business Activities'.

\footnotetext{
${ }^{3}$ An examination of the total labor force shows that relatively more female workers than male workers are professionals (34.5\% of Jewish working women, compared to $30.7 \%$ of Jewish working men). Many women work part-time (Israel, Central Bureau of Statisitcs, 1996).
} 
Comparison of male-female hourly wages shows that women, in both ethnic groups, get only about $75 \%$ of the male hourly wage. Wage differences between men and women are larger than wage differences between the ethnicities (an Easterner/Westerner wage ratio of about $82 \%$ ). Educational attainments are more similar between the sexes: The average total number of years of schooling of men and women is almost identical (16 for Westerners and 14 for Easterners), and the share of workers who have at least some academic education is even larger for women. Eastern workers are less educated than their Western co-workers - a difference of about one and a half years on average. These differences in wages and occupations between the two ethnic groups and genders reflect the stratification of Israeli society. This exists on two levels. On the ethnic level, Westerners versus Easterners, the former are more educated, have smaller families and higher occupational status and wages. Within each ethnic group, there is a second stratification level between the genders. While men and women have similar educational attainment (in some cases, female workers are more educated than their male co-workers), there is occupational segregation, whereby women are employed in less prestigious occupations and their wages are significantly lower. Gender differences in wages and in occupational segregation are more pronounced than ethnic differences despite the fact that the educational levels between the genders are more equal.

Male workers have somewhat more (potential) experience than female workers (by 1-2 years) ${ }^{4}$ and work longer hours per week (about 6 hours more). There are minor differences in these variables by ethnicity. About $60 \%$ of Jewish men (and women) are Israeli-born and the average period of residence in Israel (for workers not born in Israel) is around 30 years. More men than women are married (88\% of men compared

\footnotetext{
${ }^{4}$ Men also have more actual work experience and less interruption than women. This is evident in the more comprehensive data set linking census data with social security data: Neuman and Ziderman (2004).
} 
to $75 \%$ of women) and the average number of children is about two. ${ }^{5}$

Identification in the Selection Model It is generally appreciated that the Heckman sample selection procedure is susceptible to identification problems and sensitivity of results to model specification and distributional assumption. The difficulty of these issues for decomposition methodology is recognized in Neuman and Oaxaca (2004). Although the Heckit model can theoretically be identified by the nonlinearity of $\lambda$ even if the selection equation and the main equation have identical regressors, relying solely on nonlinearity is typically viewed as taking the low road to identification. In our specification there are a number of additional identifying restrictions which are described below.

Continuous years of schooling appear in the selection equations while degrees held appear in the wage equations to capture "sheepskin" effects. Age and its square appear in the selection equations while the closely related Mincer potential experience variable and its square appear in the wage equations. The idea here is that what matters for wages is how many years one is in the labor market. For the probability of entrance into professional employment, age might be more relevant because of potential discrimination (at the entrance level) against very young or old candidates or cohort effects might be at work. Of course if it were not for the parameter restrictions on age and experience and on their interaction and squares implied by the Mincer experience measure, there would be no differences between the selection equations and the wage equations with respect to age and experience. In the selection equation we control for Not Israeli born as there might be professional employment opportunity discrimination against non-natives. The wage equations include years

\footnotetext{
${ }^{5}$ While Eastern Israeli women have on average more children than Western women $(2.4$ and 2.0 respectively in our sample of full-time, full-year salaried women), among professional women the number is almost identical.
} 
of residence and dummy variables for branch (economic sector) while the selection equations omit these variables plus marital status. In the wage equation we include number of years of residence as this is important for wage determination (local human capital). Differences by locality (place of residence) might be important for both professional employment selection and wage determination. Economic branch is relevant for wage determination only because different branches and industries differ in the role of unions (e.g. strong union activity in electricity), bargaining power of workers or employers, type of labor contracts (e.g. many workers attached to employment agencies in some industries) etc. Evidence in favor of the view that the apparent wage effects of marital status stem from selection effects is presented in Krashinsky (2000). The Krashinsky study uses data on a sample of twins and finds that unlike the standard human capital variables and union effects, marital status does not significantly affect wages after selection is accounted for. This finding is an example of the point made in Heckman (1979) that variables that may have no direct effect on wages may appear to do so if they are operating at the sample selection stage.

The lure of simplicity has to be weighed against the possible consequences of identification problems associated with the Heckman method. Accordingly, our results reported below have to be viewed with the usual caveats.

Selection Equations We now examine the respective probabilities of employment in the professional occupations. Probit models are estimated in which the dependent variable takes on the value of 1 if the worker is employed in the professional occupations and 0 if the worker is employed in other occupations. ${ }^{6}$ The estimates of the probit regressions are used to construct the Inverse Mills Ratio for the purpose of correcting professional hourly wage equations for selection bias and are reported in Table 2. Predictably, schooling has a major positive effect on the probability of being

\footnotetext{
${ }^{6}$ Non-employed individuals are excluded from the sample.
} 
employed as a professional worker for all groups. Age has parabolic effects that vary across groups. Over a normal working life age generally exhibits a positive effect on the probability of professional employment for all groups; however for women the age effect is increasing whereas for men it is declining. Married Westerners have a higher probability of professional employment. For Eastern workers the effect is insignificant. Number of children was never statistically significant and was subsequently dropped without altering any of the basic conclusions. Male workers not born in Israel have a lower tendency to work as professionals while female workers not born in Israel have a greater propensity to be employed as professionals. City of residence is generally statistically significant for women but not generally so for men. The effect of the size of locality of residence is generally significant for women and Western men, but not so for Eastern men.

Wage Equations Mincer-type wage equations corrected for selectivity in professional occupation are estimated in order to study the wage structure of each gender (by ethnic group). These equations are later used to calculate the share of the human capital (explained) component versus the discrimination (unexplained) component and the selectivity component in explaining wage differentials between the various groups. In all wage regressions (Table 3), the logarithm of individual hourly wages is regressed against the following explanatory variables: dummy variables representing the highest educational certificate obtained, years of potential work experience (age - years of schooling - 6), experience squared, a dummy variable for foreign born, the length of residence in Israel, dummy variables for city and size of locality and the economic sector in which the worker is employed (a series of dummy variables for one-digit economic sectors).

The results of the regressions conform to the results found in numerous other studies: earnings are increasing with the (higher) degree or certificate obtained, the re- 
lationship between earnings and experience has the inverted U-shape, and length of residence in Israel is positively related to earnings. ${ }^{7}$ The magnitudes of the effects of the various explanatory variables on earnings are less straightforward. There are gender differences in the returns to the human capital variables. Returns to experience are larger for men than for women, as well as to years of residence in Israel. On the other hand the returns to education and to the size of locality are higher for women, and the wage penalty associated with being foreign born is smaller for women. There are also differences between the ethnic groups. Educational attainment has a stronger effect on the wages of Easterners. The wage penalty for not being Israeli born is higher for Westerners. The overall picture shows that returns to education are higher for subordinate groups of workers, while returns to experience and residence (experience in the labor market) are higher in the superior group. For example, returns to a BA degree are greatest for Eastern women (coefficient 0.433 compared to elementary school education as a reference group) and lowest for Western men (0.287). Western women and Eastern men are between these values (0.344 and 0.354, respectively). The same ranking is found for the Ph.D. degree: the highest return for Eastern women (0.646), the lowest for Western men (0.375) and, between these two extremes, Western women (0.466) and Eastern men (0.536). A similar pattern is found at all other levels.

For experience (potential) and residence in the country, the reverse pattern is found: Western men show the highest returns to both experience (0.052) and per year of residence (0.006). The other three groups have lower and very similar returns.

\footnotetext{
${ }^{7}$ It should be noted that the length of residence in the country is one of the elements of human capital, since it presumably measures the degree of understanding of the operation of the local labor market and also, which is most important, the command of the spoken language, i.e., the ability to communicate verbally. (On language and earnings, see Chiswick and Miller (1995)).
} 
Empirical studies for other countries give mixed results. For example, in a series of papers on returns to education in 15 European countries (Asplund and Pereira, 1999), the rates of return are higher for men in several countries (Denmark, Finland and France). In Greece and Italy, they are higher for women and, in Germany, returns are higher for women in one of the samples but lower in the others.

Selection Estimates A sense of the role of selection effects in determining wages can be determined from Table 4 which presents the estimates of the averages of the $I M R$ variable $(\lambda)$ and the respective coefficients of this variable in the wage equations $(\theta)$. The coefficient of $\lambda$ is negative and statistically significant in all cases. Since $\lambda$ is inversely related to the probability of employment in the professional occupation, a negative coefficient indicates that (cet. par.) workers with higher probabilities of being employed in the professional occupation will earn higher wages conditional upon employment in the professional occupation.

The estimates of $\lambda$ are higher for women and for Easterners which is consistent with the lower probabilities for members of these groups being employed as professionals. Adopting the estimated probit coefficients of males (Westerners) further increases the value of $\lambda$ for females (Easterners). This implies that the probit weights for females (Easterners) favor higher probabilities of professional employment compared with the probit weights for males (Westerners). Furthermore, the personal characteristics of females (Easterners) favor lower probabilities of professional employment compared with the personal characteristics of males (Westerners).

IV. Decomposition of Wage Differentials and the Role of Selectivity Table 5 presents the decomposition for the various comparisons. There are five decomposition corresponding to each comparison. First as a benchmark is the standard Oaxaca (1973) decomposition technique. This is followed by the four decompositions 
incorporating selection effects. We label the selectivity corrected decompositions decomposition \#1 - decomposition \#4 corresponding to expressions (7), (10), (11), and (12). By construction, the discrimination estimates for decompositions \#2 and \#4 are identical as are the estimated human capital contributions for decompositions \#3 and \#4. For economy of notation when analyzing ethnic wage differentials, we will let ' $m$ ' and ' $f$ ' denote Westerner and Easterner, respectively.

The overall results are the following. Gender wage differentials (at the mean points) are larger than ethnic wage differentials. Among both Westerners and Easterners Jewish men earn $26 \%$ more (per hour) than Jewish women, while among both men and women Westerners earn 19\% more than Easterners. When professional employment probabilities are not taken into account (no selectivity correction), differences in characteristics explain between $36 \%$ and $74 \%$ of the wage differentials. The explained share is smallest (36\%) in a gender comparison among Westerners and largest (74\%) in an ethnic comparison of women.

It is evident from Table 5 that the decomposition results are acutely sensitive to assumptions about how or whether to incorporate selection effects. For example, ethnic comparisons among women indicate that without correction for selectivity estimated discrimination against Eastern women accounts for about $26.4 \%$ of the ethnic (log) wage gap. Yet correcting for selection bias suggests that favoritism toward Eastern women vis $\mathrm{a}^{\prime}$ vis Western women could be as high as $-43.4 \%$ of the wage gap. Similar results are obtained for ethnic comparisons among men. In the case of gender comparisons, all of the decompositions employed yield positive estimates of discrimination against women. However, the estimates vary widely across alternative decompositions. For example the unexplained gender wage gap among Easterners varies from $63.4 \%$ of the total gap if selection is not taken into account to $22.7 \%$ of the gap under decomposition \#4.

Selection contributes to a narrowing of the observed gender wage gap among West- 
erners. This is attributable to the fact that the wage effect of $\lambda$ is more negative for Western men $\left(\left(\widehat{\theta}_{m}-\widehat{\theta}_{f}\right) \widehat{\lambda}_{f}<0\right)$, and the estimated Western male selection equation lowers the probability of professional employment for the average Western female professional worker $\left(\widehat{\theta}_{m}\left(\widehat{\lambda}_{f}^{0}-\widehat{\lambda}_{f}\right)<0\right)$. What this means is that the conditional mean value of the wage equation error term for professional workers is lower on average for Western men than for Western Women. In other words relatively higher earnings potential women are employed in the professional occupations. This is in contrast to the ethnic comparisons and the gender comparison among Easterners. For example, the conditional mean value of the wage equation error term for professional workers is higher on average for Westerners (Eastern men) than Easterners (Eastern women). In other words selection increases the observed ethnic (Eastern gender) wage gap because relatively lower earnings potential Easterners (Eastern women) are employed in the professional occupations. For the ethnic comparison among men, selection has a partial negative impact on the wage gap in decomposition \#1 $\left.\left(\widehat{\theta}_{m}-\widehat{\theta}_{f}\right) \widehat{\lambda}_{f}<0\right)$, but overall this is more than offset by the other components of the selection decomposition as evidenced in selection decomposition \#1 $\left(\widehat{\theta}_{m} \widehat{\lambda}_{m}-\widehat{\theta}_{f} \widehat{\lambda}_{f}>0\right)$.

Within any comparison group in Table 5 , the estimated discrimination and endowment components can vary a great deal as a result of the imputation of gender differences in the selectivity term. Because of the different possible imputations of decomposition components of gender differences in selectivity effects, estimates of discrimination and endowment effects can vary widely even if the overall gender difference in the selectivity term is relatively modest. For example, the contribution of overall gender differences in selectivity effects is only $-5.41 \%$ of the total gender wage gap among Westerners. Yet discrimination can account from $38 \%$ to $67 \%$ of the overall wage gap. This variation is not simply statistical variation but rather the consequence of what one chooses to label as discrimination (or endowments). In our sample women are less likely to be employed in the professional occupations, 
though the estimated coefficients on the determinants of professional employment favor women. If a policy maker were primarily interested in direct salary equity rather than selection effects, decomposition \#1 would provide the relevant target adjustments. Note that this does not completely ignore the effects of selectivity because the implied estimates of discrimination are generally different from what they would be under the standard Oaxaca decomposition which does not control for selectivity. Successful implementation of policies using decomposition \#1 as a guideline would raise the wages of women relative to men and would raise the wages of Eastern men relative to Western men.

\section{Concluding Remarks}

The presence of selection effects narrows the observed gender wage gap among professionally employed Westerners but raises the gender gap among Easterners. On the other hand selection effects reduce the observed ethnic wage gap among professionally employed men but raise the ethnic wage gap among professionally employed women. Without exception, gender and ethnic differences in the characteristics determining selection into professional employment serve to diminish the observed wage gaps. Also without exception, gender and ethnic differences in the probit selection equation parameters serve to widen the observed wage gaps. Any anti-discrimination policy directed at muting gender and ethnic differences in the weights placed on characteristics that determine selection into professional employment would first have to identify how much of the parameter differences can be associated with supply side influences and how much represent unequal access to professional employment. This is no easy task.

If one sets aside the contribution of the estimated selection effects to the observed wage differentials (decomposition \#1), generally the estimated discrimination component is the highest. In this case the emphasis for anti-discrimination policy would 
be on wage structure for professionals. The only exception is for ethnic differentials among women. Here the largest unexplained gaps occur for decompositions \#2 and \#4. Here the difference is that decomposition \#2 assigns all of the selection contributions to either discrimination or endowments while decomposition \#4 identifies the selection effect as stemming solely from differences in the $I M R$ on professional wages.

What this paper has shown is that in addition to gender differences exceeding ethnic differences, selection effects do impact estimates of labor market discrimination. At the very least taking account of selection effects into professional employment reveals what the gender and ethnic wage gaps would have looked like in the absence of these effects. Decomposition \#1 reveals that in the absence of selection effects, the gender wage gap would have been lower among Westerners. By the same token the same time ethnic wage gaps and the gender wage gap among Easterners would have been larger.

The question of why selection effects 1) narrow the gender wage gap among Westerners, 2) raise the gender wage gap among Easterners, and 3) raise the ethnic wage gap for both men and women is ultimately a question of why there are group differences in the effects of selection characteristics, in selection characteristics themselves, and the wage effects of selection. These are the component terms of the decomposition of the conditional expectation of the wage error terms for selected samples as given by (9). Unfortunately, there is no ready answer to what in the Israeli labor market could account for the pattern of differences in the effects of selection on gender and ethnic wage gaps. Although we excluded recent immigrants from our analysis, there are still immigrants in the sample. The great majority of them are immigrants from Western countries (mainly the former USSR). Only a negligible number of immigrants are from Eastern countries. Part of the selection against Westerners (negative selection of Easterners) is probably related to the fact that among Westerners there 
is a significant number of immigrants who are discriminated against at the selection (entrance) stage. This is properly a topic for future research.

To better understand in general how selection impacts estimates of discrimination, we can compare decompositions \#2 and \#3 which allocate all of the selection effects to either discrimination or endowments with decomposition \#1 which does not allocate selection effects. Without exception the allocation of selection effects lowers (raises) the estimate of discrimination (endowments). Even a partial allocation of selection effects in decomposition \#4 raises the estimate of discrimination and lowers the estimate of endowments compared with decomposition \#1. Although one would like to be more precise, it can be inferred that at least some of what one might believe to be direct labor market salary inequity is actually the observed wage consequences of selection into professional employment. This goes back to the fundamental issue that is present in virtually all empirical studies of labor market discrimination, i.e. how much of the observed gender and ethnic differences in labor market outcomes is the result of voluntary labor supply choices? Our research on professionals in the Israeli labor market has at least uncovered additional facets of this identification problem.

\section{REFERENCES}

Asplund, Rita and Pereira, Pedro T. (eds.) (1999). Returns to Human Capital in Europe. ELTA, The Research Institute of the Finnish Economy.

Bergmann, Barbara R. (1974). "Occupational Segregation, Wages and Profits When Employers Discriminate by Race or Sex," Eastern Economic Journal 1(2), 103-10.

Bergmann, Barbara R. (1986). The Economic Emergence of Women, New York: Basic Books. 
Bergmann, Barbara R. (1996). In Defense of Affirmative Action, New York: Basic Books.

Blau, Francine D.and Ferber, Marianne A. (1992). The Economics of Women, Men and Work, Prentice-Hall, Englewood Cliffs, New -Jersey.

Blau, Francine D. and Kahn, Lawrence M. (2003). "Understanding International Differences in the Gender Pay Gap," Journal of Labour Economics 21(1), 106-44.

Blinder, Alan S. (1973). "Wage Discrimination: Reduced Form and Structural Estimates," Journal of Human Resources 8, 436-455.

Boymond, Martine, Yves Flückiger and Jacques Silber. (1994) "Wage Discrimination and Occupational Segregation by Gender: Some Evidence from Swiss Data," Départment d'Economie Politique, Université de Genèva, mimeo.

Brown, Randall, Marilyn Moon, and Barbara S. Zoloth. (1980). "Incorporating Occupational Attainment in Studies of Male-Female Earnings Differentials," Journal of Human Resources 15(1), 3-28.

Chiswick Barry R. and Paul W. Miller.(1995). "The Endogeneity Between Language and Earnings: International Analyses," Journal of Labor Economics $13(2), 245-287$.

Cohen Yinon,Yitchak Haberfeld,Guy Mundlak, and Yitchak Saporta (2001). "Unionization Rate and Coverage of Collective Agreements," Jerusalem: Ministry of Labour and Social Affairs.

Duncan, Gregory M. and Duane E. Leigh. (1980). "Wage Determination in the Union and Nonunion Sectors: A Sample Selectivity Approach," Industrial and Labor Relations Review, 34, 24-34. 
Gronau, Reuben. (1974). "Wage Comparisons: A Selectivity Bias," Journal of Political Economy 82, 1119-1143.

Heckman, James. (1976). "The Common Structure of Statistical Models of Truncation, Sample Selection and Limited Dependent Variables and a Simple Estimator for Such Models," Annals of Economic and Social Measurement 5(4), 475-492.

Heckman, James. (1979) "Sample Selection Bias as a Specification Error," Econometrica $47,153-163$.

Hirsch, Barry T. and David A. Macpherson. (1994). "Wages, Racial Composition, and Quality Sorting in Labor Markets," Discussion Paper no. 1038-94, Madison, WI: Institute for Research on Poverty.

Hirsch, Barry T. and Edward J. Schumacher. (1992). "Labor Earnings, Discrimination, and the Racial Composition of Jobs," Journal of Human Resources 27, 426-470.

Israel. (1996). Statistical Abstract of Israel, Central Bureau of Statistics.

Israel. (1998). "Census of Population and Housing 1995," in Statistical Abstract of Israel, Central Bureau of Statistics.

Jacobsen, Joyce P. (1994).The Economics of Gender, Balckwell, Cambridge, MA.

Krashinsky, H. (2000). "Do Marital Status and Computer Usage Really Change the Wage Structure? Evidence from a Sample of Twins," Princeton University Industrial Relations Section Working Paper, June.

Macpherson, David A. and Barry T. Hirsch. (1995). "Wages and Gender Composition: Why Do Women's Jobs Pay Less?," Journal of Labor Economics 13, 426-471. 
Miller, Paul, W. (1987). "The Effect of the Occupational Segregation of Women in Britain," The Economic Journal 97, 885-896.

Neuman, Shoshana and Ronald L. Oaxaca (2003). "Gender Versus Ethnic Wage Differentials Among Professionals: Evidence from Israel, "Annales D'Économie et de Statistique, 71-72, July/December, 267-292.

Neuman, Shoshana and Ronald L. Oaxaca (2004). "Wage Decompositions with Selectivity Corrected Wage Equations: A Methodological Note," Journal of Economic Inequality 2, 3-10.

Neuman, Shoshana and Jacques Silber. (1996). "Wage Discrimination Across Ethnic Groups: Evidence from Israel," Economic Inquiry 34(4), 648-661.

Neuman, Shoshana and Jacob Weisberg. (1998). "Gender Wage Differentials and Discrimination Among Israeli Managers," International Journal of Manpower 19 (3), 161-170.

Neuman, Shoshana and Adrian Ziderman. (2003). "Work Histories of Israeli Men and Women, 1983-1995," The Pinhas Sapir Center for Development, Tel-Aviv University. Discussion Paper OP \#6-2003.

Neumark, David. (1988). "Employers' Discriminatory Behavior and the Estimation of Wage Discrimination," Journal of Human Resources 23, 279-295.

Oaxaca, Ronald L.(1973). "Male-Female Wage Differentials in Urban Labor Markets," International Economic Review 14, 693-709.

Oaxaca, Ronald L. and Michael R. Ransom. (1988). "Searching for the Effect of Unionism on the Wages of Union and Nonunion Workers," Journal of Labor Research 9, 139-148. 
Oaxaca, Ronald L. and Michael R. Ransom. (1994). "On Discrimination and the Decomposition of Wage Differentials," Journal of Econometrics 61, 5-21.

Polachek, Solomon W. (1975). "Differences in Expected Post-School Investment as a Determinant of Market Wage Differentials," International Economic Review $16,451-70$.

Polachek, Solomon W. (1976). "Occupational Segregation: An Alternative Hypothesis." Journal of Contemporary Business 5, 1-12.

Polachek, Solomon W. (1979)."Occupational Segregation Among Women: Theory, Evidence and a Prognosis." In Cynthia Lloyd, Emily Andrews and Curtis Gilroy (eds.), Women in the Labor Market. New York, Columbia University Press, pp. 1-12.

Polachek, Solomon W. and Moon-Kak Kim. (1994). "Panel Estimates of the Gender Earnings Gap: Individual-Specific Intercept and Individual-Specific Slope Models," Journal of Econometrics 61(1), 23-42.

Reilly, Barry. (1991). "Occupational Segregation and Selectivity Bias in Occupational Wage Equations: An Empirical Analysis using Irish Data," Applied Economics 23, 1-7.

Reimers, Cordelia. (1983). "Labor Market Discrimination Against Hispanic and Black Men," The Review of Economics and Statistics 65, 570-79. 
TABLE 1: Sample Characteristics by Ethnic Origin

Israeli Women and Men, 25-65 Year-Olds, Full-Time Salaried Professionals - Israeli Census, 1995

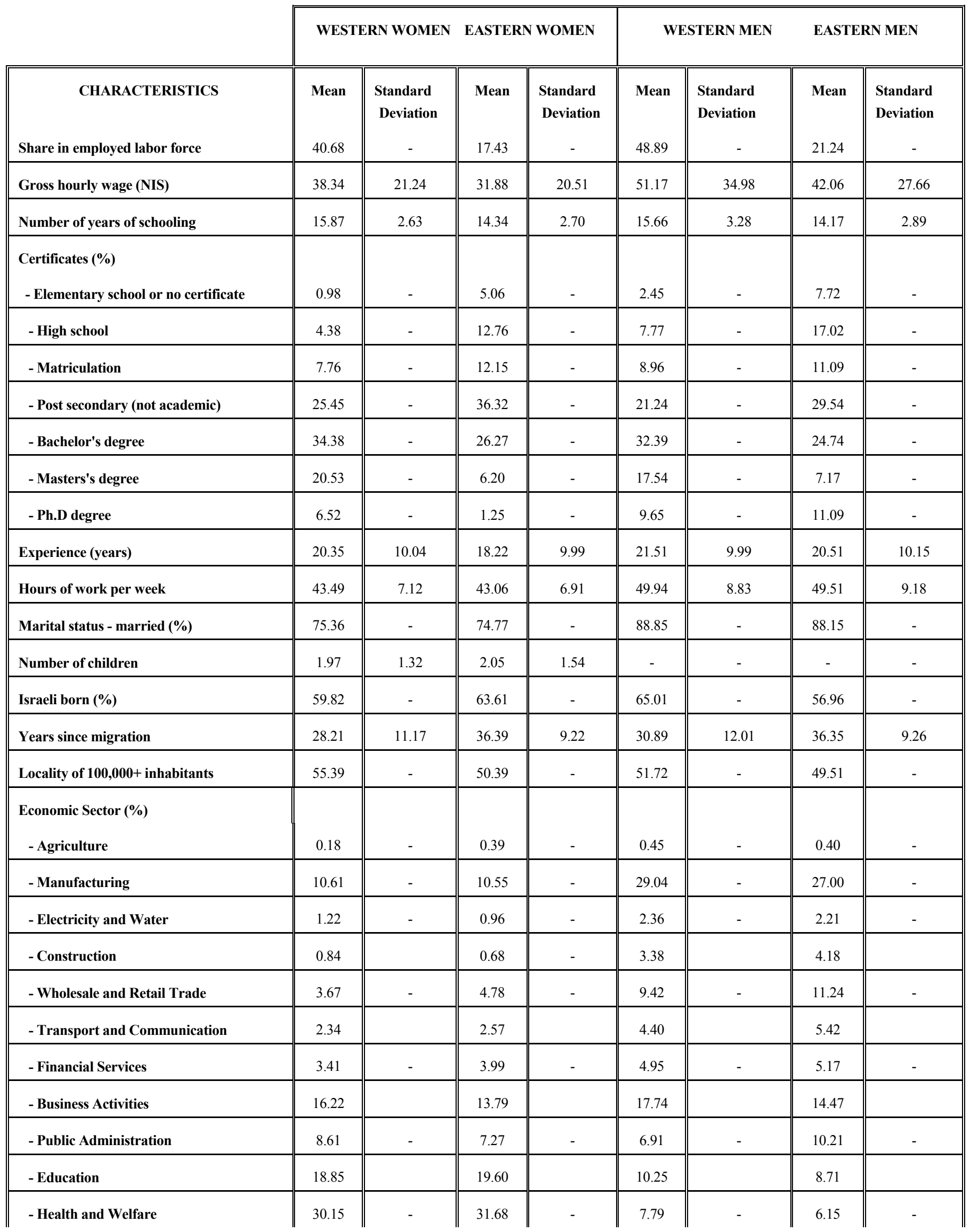




\begin{tabular}{|l||c||c||c||c||c||c||c||}
\hline - Other Personal Services & 3.89 & - & 3.74 & - & 3.30 & - & 4.84 \\
\hline Sample size & 7,268 & - & 2,806 & - & 14,336 & - & 6,052 \\
\hline
\end{tabular}

Notes: A worker is referred to as a Westerner if he was born in Europe, America, South Africa or Australia, or if he is Israeli-born and his father was born in one of these places. An Easterner is a worker who was born in Asia or Africa (excluding South Africa and Israel), or if he is Israeli born and his father was born in Asia/Africa. Second generation Israelis are part of the Western group. 
Table 2

Probit Model of Employment in the Professional Occupations Israeli Women and Men, 25-65 Year-Olds, Full-Time Salaried Professionals Israeli Census, 1995

\begin{tabular}{|c|c|c|c|c|}
\hline \multirow[b]{2}{*}{ INDEPENDENT VARIABLES } & \multicolumn{2}{|c|}{ Women } & \multicolumn{2}{|c|}{ Men } \\
\hline & Western & Eastern & Western & Eastern \\
\hline Years of schooling & $0.289(65.86)$ & $0.302(50.36)$ & $0.252(81.95)$ & $0.287(71.58)$ \\
\hline Age & $-0.012(1.38)$ & $-0.026(2.16)$ & $0.032(4.71)$ & $0.040(4.92)$ \\
\hline Age squared & $0.0002(2.06)$ & $0.0005(3.26)$ & $-0.0003(3.56)$ & $-0.0003(3.29)$ \\
\hline Not Israeli born & $0.118(5.04)$ & $0.086(2.58)$ & $-0.732(4.02)$ & $-0.008(0.34)$ \\
\hline $\begin{array}{ll}\text { Place of residence } \\
\text { - } & \text { Jerusalem } \\
\text { - } & \text { Tel Aviv } \\
\text { - } & \text { Haifa } \\
\text { - } & \text { Locality of } 100-200 \text { thousand } \\
\text { - } & \text { Locality of } 10-100 \text { thousand } \\
\text { - } & \text { Locality of 2-10 thousand }\end{array}$ & $\begin{array}{l}-0.112(2.08) \\
-0.139(2.72) \\
-0.064(1.16) \\
-0.200(4.381) \\
-0.165(3.70) \\
-0.132(2.11)\end{array}$ & $\begin{array}{l}-0.188(2.82) \\
-0.075(1.10) \\
-0.204(2.46) \\
-0.248(4.48) \\
-0.169(3.13) \\
-0.128(1.75)\end{array}$ & $\begin{array}{r}-0.040(0.93) \\
0.018(0.44) \\
0.041(0.99) \\
-0.116(3.40) \\
-0.089(2.70) \\
-0.081(1.79)\end{array}$ & $\begin{array}{c}0.047(0.92) \\
0.015(0.28) \\
0.170(2.78) \\
-0.042(1.03) \\
-0.069(1.73) \\
0.043(0.81)\end{array}$ \\
\hline Marital status: married & $0.067(2.63)$ & $-0.014(0.45)$ & $0.060(2.28)$ & $-0.008(0.26)$ \\
\hline $\begin{array}{l}\text { Intercept } \\
\text { Sample size }\end{array}$ & $\begin{array}{c}-4.171(21.36) \\
17,865\end{array}$ & $\begin{array}{c}-4.353(17.10) \\
16,094\end{array}$ & $\begin{array}{c}-4.337(29.82) \\
29,320\end{array}$ & $\begin{array}{c}-5.394(30.49) \\
28,486\end{array}$ \\
\hline
\end{tabular}

Notes:

For the definition of Western and Eastern see notes of Table 1

Dependent variable $=1$ if in professional occupations, and 0 if in other occupations.

Numbers in parentheses are absolute t-statistics.

Reference group for marital status: single; either bachelor, divorced or widowed.

Reference group for place of residence: agricultural localities.

Samples include professionals and employed in other occupations. New immigrants (less than 10 years in Israel) are excluded. 
Table 3

\section{Log Hourly Wage Regressions Israeli Women and Men, 25-65 Year-Olds, Full-Time Salaried Professionals Israeli Census, 1995}

\begin{tabular}{|c|c|c|c|c|}
\hline \multirow{2}{*}{ INDEPENDENT VARIABLES } & \multicolumn{2}{|c|}{ Women } & \multicolumn{2}{|c|}{ Men } \\
\hline & Western & Eastern & Western & Eastern \\
\hline \multicolumn{5}{|l|}{ Highest certificate obtained } \\
\hline - $\quad$ High school & $0.069(1.07)$ & $0.037(0.74)$ & $0.050(1.51)$ & $0.069(2.29)$ \\
\hline - Matriculation & $0.143(2.26)$ & $0.170(3.18)$ & $0.119(3.52)$ & $0.171(4.94)$ \\
\hline - $\quad$ Post secondary (not academic) & $0.190(2.99)$ & $0.218(3.99)$ & $0.106(3.09)$ & $0.202(5.82)$ \\
\hline - Bachelor's degree & $0.344(5.15)$ & $0.433(6.84)$ & $0.287(7.61)$ & $0.354(8.49)$ \\
\hline - $\quad$ Master's degree & $0.374(5.32)$ & $0.364(4.76)$ & $0.350(8.48)$ & $0.443(8.70)$ \\
\hline - $\quad P h . D$ & $0.466(6.20)$ & $0.646(5.93)$ & $0.375(8.34)$ & $0.536(8.56)$ \\
\hline Experience & $0.045(19.33)$ & $0.048(13.54)$ & $0.052(28.09)$ & $0.044(16.50)$ \\
\hline Experience squared & $-0.0007(12.65)$ & $-0.0007(9.31)$ & $-0.0007(18.83)$ & $-0.0005(9.28)$ \\
\hline Not Israeli born & $-0.139(5.14)$ & $-0.119(1.88)$ & $-0.256(11.40)$ & $-0.173(4.14)$ \\
\hline Years of residence & $0.002(2.61)$ & $0.002(1.29)$ & $0.006(9.27)$ & $0.004(3.44)$ \\
\hline \multicolumn{5}{|l|}{ Place of residence } \\
\hline - $\quad$ Jerusalem & $0.091(3.29)$ & $0.043(0.99)$ & $0.051(2.26)$ & $-0.005(0.17)$ \\
\hline - $\quad$ Tel Aviv & $0.135(5.01)$ & $0.029(0.67)$ & $0.092(4.26)$ & $0.007(0.21)$ \\
\hline - $\quad$ Haifa & $0.113(4.06)$ & $0.028(0.52)$ & $0.041(1.89)$ & $0.040(1.07)$ \\
\hline - Locality of 100-200 thousand & $0.128(5.25)$ & $0.059(1.61)$ & $0.051(2.73)$ & $0.023(0.89)$ \\
\hline - $\quad$ Locality of 10-100 thousand & $0.129(5.55)$ & $0.024(0.70)$ & $0.088(4.94)$ & $0.035(1.33)$ \\
\hline - $\quad$ Locality of 2-10 thousand & $0.160(4.93)$ & $0.083(1.71)$ & $0.111(4.60)$ & $0.046(1.33)$ \\
\hline \multicolumn{5}{|l|}{ Economic Branch } \\
\hline - $\quad$ Manufacturing & $0.295(2.15)$ & $0.169(1.19)$ & $0.231(4.50)$ & $0.260(2.57)$ \\
\hline - $\quad$ Electricity and water & $0.479(3.29)$ & $0.309(1.86)$ & $0.304(4.25)$ & $0.344(3.15)$ \\
\hline - Construction & $0.232(1.55)$ & $0.271(1.54)$ & $0.128(1.84)$ & $0.216(2.06)$ \\
\hline - Wholesale and retail trade & $0.229(1.64)$ & $0.096(0.66)$ & $0.201(3.00)$ & $0.226(2.22)$ \\
\hline - Transportation and communication & $0.355(2.51)$ & $0.306(2.04)$ & $0.371(5.40)$ & $0.406(3.90)$ \\
\hline - $\quad$ Financial services & $0.627(4.49)$ & $0.463(3.16)$ & $0.501(7.32)$ & $0.594(5.68)$ \\
\hline - $\quad$ Real estate and business activities & $0.285(2.08)$ & $0.204(1.44)$ & $0.153(2.30)$ & $0.228(2.24)$ \\
\hline - $\quad$ Public services & $0.336(2.45)$ & $0.097(0.68)$ & $0.138(2.04)$ & $0.236(2.31)$ \\
\hline - $\quad$ Education & $0.089(0.65)$ & $-0.160(1.13)$ & $-0.028(0.40)$ & $0.056(0.54)$ \\
\hline - Health and welfare & $0.260(1.90)$ & $0.084(0.60)$ & $0.474(0.70)$ & $0.137(1.32)$ \\
\hline - $\quad$ Private services & $0.144(1.03)$ & $0.011(0.08)$ & $0.407(0.59)$ & $0.100(0.96)$ \\
\hline Lambda & $-0.165(6.66)$ & $-0.196(6.84)$ & $-0.212(9.30)$ & $-0.188(8.22)$ \\
\hline Constant & $2.429(15.51)$ & $2.631(16.02)$ & $2.740(33.40)$ & $2.661(22.56)$ \\
\hline $\mathrm{R}^{2}$ & 0.1973 & 0.2638 & 0.2240 & 0.2638 \\
\hline Sample size & 7,268 & 2,806 & 14,336 & 6,052 \\
\hline Percent of professional & 40.68 & 17.43 & 48.89 & 21.24 \\
\hline
\end{tabular}


Notes:

For the definition of Western and Eastern see notes of Table 1

Numbers in parentheses are absolute t-statistics.

Reference group for: 'Highest certificate obtained' is 'Elementary school certificate.'

Reference group for: 'Place of residence' is 'Localities with less than 2 thousand inhabitants and agricultural localities'.

Reference group for 'Economic branch' is 'Agriculture'.

New immigrants (less than 10 years in Israel) are excluded from the samples. 
TABLE 4: Estimates of Average Lambdas and Lambda's Coefficients

\begin{tabular}{|c|c|c|c|c|c|c|c|c|c|c|}
\hline Wage differential & $\hat{\lambda}_{m}$ & $\hat{\lambda}_{f}$ & $\hat{\lambda}_{f}^{0}$ & $\hat{\theta}_{m}$ & $\hat{\theta}_{f}$ & $Z_{1}$ & $Z_{2}$ & $Z_{3}$ & $Z_{4}$ & $Z_{5}$ \\
\hline & & & & \multicolumn{2}{|c|}{ Westerners: Men-Women } & & & & & \\
\hline \multirow[t]{2}{*}{0.2567} & 0.6206 & 0.7121 & 0.9128 & -0.2119 & -0.1651 & 0.0976 & 0.0619 & -0.0333 & 0.1730 & -0.0425 \\
\hline & & & & \multicolumn{2}{|c|}{ Easterners: Men-Women } & & & & & \\
\hline \multirow[t]{2}{*}{0.2623} & 1.0313 & 1.1362 & 1.5080 & -0.1875 & -0.1962 & 0.1036 & 0.0894 & 0.0098 & 0.1292 & -0.0697 \\
\hline & & & & \multicolumn{2}{|c|}{ Men: Westerners-Easterners } & & & & & \\
\hline \multirow[t]{2}{*}{0.1871} & 0.6206 & 1.0313 & 1.3524 & -0.2119 & -0.1875 & 0.0776 & 0.1551 & -0.0252 & 0.0476 & -0.0680 \\
\hline & & & & \multicolumn{2}{|c|}{ Women: Westerners- Easterners } & & & & & \\
\hline 0.1927 & 0.7121 & 1.1363 & 1.5400 & -0.1651 & -0.1962 & 0.1044 & 0.1367 & 0.0353 & -0.0170 & -0.0666 \\
\hline
\end{tabular}

NOTES: $\lambda_{m}, \lambda_{f}$ are averages of the inverse of Mill's ratios, for men and women (or Westerners and Easterners), respectively. $\hat{\theta}_{m}, \hat{\theta}_{f}$ are estimates of the coefficients of $\hat{\lambda}_{m}, \hat{\lambda}_{f}$ in the corrected wage equations.

Legend:

$$
\begin{aligned}
& Z_{1}=\left(\bar{X}_{m}-\bar{X}_{f}\right)^{\prime} \hat{\beta}_{m} \\
& Z_{2}=\hat{\theta}_{m}\left(\hat{\lambda}_{m}-\hat{\lambda}_{f}^{0}\right) \\
& Z_{3}=\left(\hat{\theta}_{m}-\hat{\theta}_{f}\right) \hat{\lambda}_{f} \\
& Z_{4}=\bar{X}_{f}^{\prime}\left(\hat{\beta}_{m}-\hat{\beta}_{f}\right) \\
& Z_{5}=\hat{\theta}_{m}\left(\hat{\lambda}_{f}^{0}-\hat{\lambda}_{f}\right)
\end{aligned}
$$


TABLE 5: Decompositions of Wage Differentials

Israeli, Jewish, 25-65 year olds, salaried professionals

Israeli Census, 1995

\begin{tabular}{|c|c|c|c|c|}
\hline \multirow[b]{2}{*}{ Decomposition method } & \multirow[b]{2}{*}{ Wage differential } & \multicolumn{3}{|c|}{ Contribution of } \\
\hline & & $\mathrm{H}$ & $\mathrm{D}$ & Selectivity \\
\hline & & \multicolumn{3}{|c|}{ Westerners: Men-Women } \\
\hline Standard Oaxaca & 0.2567 & $\begin{array}{c}0.0916 \\
(35.68 \%)\end{array}$ & $\begin{array}{c}0.1651 \\
(64.32 \%)\end{array}$ & $\begin{array}{c}0.0000 \\
(0.00 \%)\end{array}$ \\
\hline Decomposition \# 1 & & $\begin{array}{c}0.0976 \\
(38.02 \%)\end{array}$ & $\begin{array}{c}0.1730 \\
(67.39 \%)\end{array}$ & $\begin{array}{c}-0.0139 \\
(-5.41 \%)\end{array}$ \\
\hline Decomposition \# 2 & & $\begin{array}{c}0.1262 \\
(49.16 \%)\end{array}$ & $\begin{array}{c}0.1305 \\
(50.84 \%) \\
\end{array}$ & $\begin{array}{c}0.0000 \\
(0.00 \%) \\
\end{array}$ \\
\hline Decomposition \# 3 & & $\begin{array}{c}0.1595 \\
(62.13 \%)\end{array}$ & $\begin{array}{c}0.0972 \\
(37.87 \%)\end{array}$ & $\begin{array}{c}0.0000 \\
(0.00 \%)\end{array}$ \\
\hline \multirow[t]{2}{*}{ Decomposition \# 4} & & $\begin{array}{c}0.1595 \\
(62.13 \%)\end{array}$ & $\begin{array}{c}0.1305 \\
(50.84 \%)\end{array}$ & $\begin{array}{c}-0.0333 \\
(-12.97 \%)\end{array}$ \\
\hline & & \multicolumn{3}{|c|}{ Easterners: Men-Women } \\
\hline Standard Oaxaca & 0.2623 & $\begin{array}{c}0.0959 \\
(36.56 \%)\end{array}$ & $\begin{array}{c}0.1664 \\
(63.44 \%)\end{array}$ & $\begin{array}{c}0.0000 \\
(0.00 \%)\end{array}$ \\
\hline Decomposition \# 1 & & $\begin{array}{c}0.1036 \\
(39.50 \%)\end{array}$ & $\begin{array}{c}0.1292 \\
(49.26 \%)\end{array}$ & $\begin{array}{c}0.0295 \\
(11.24 \%)\end{array}$ \\
\hline Decomposition \# 2 & & $\begin{array}{c}0.2028 \\
(77.32 \%)\end{array}$ & $\begin{array}{c}0.0595 \\
(22.68 \%)\end{array}$ & $\begin{array}{c}0.0000 \\
(0.00 \%)\end{array}$ \\
\hline Decomposition \# 3 & & $\begin{array}{c}0.1930 \\
(73.58 \%)\end{array}$ & $\begin{array}{c}0.0693 \\
(26.42 \%)\end{array}$ & $\begin{array}{c}0.0000 \\
(0.00 \%)\end{array}$ \\
\hline \multirow[t]{2}{*}{ Decomposition \# 4} & & $\begin{array}{c}0.1930 \\
(73.58 \%)\end{array}$ & $\begin{array}{c}0.0595 \\
(22.68 \%)\end{array}$ & $\begin{array}{c}0.0098 \\
(3.74 \%)\end{array}$ \\
\hline & & \multicolumn{3}{|c|}{ Men: Westerners-Easterners } \\
\hline Standard Oaxaca & 0.1871 & $\begin{array}{c}0.1200 \\
(64.14 \%)\end{array}$ & $\begin{array}{c}0.0671 \\
(35.86 \%)\end{array}$ & $\begin{array}{c}0.0000 \\
(0.00 \%)\end{array}$ \\
\hline Decomposition \# 1 & & $\begin{array}{c}0.0776 \\
(41.48 \%)\end{array}$ & $\begin{array}{c}0.0476 \\
(25.44 \%)\end{array}$ & $\begin{array}{c}0.0619 \\
(33.08 \%) \\
\end{array}$ \\
\hline Decomposition \# 2 & & $\begin{array}{c}0.2075 \\
(110.90 \%)\end{array}$ & $\begin{array}{c}-0.0204 \\
(-10.90 \%)\end{array}$ & $\begin{array}{c}0.0000 \\
(0.00 \%)\end{array}$ \\
\hline Decomposition \# 3 & & $\begin{array}{c}0.2327 \\
(124.37 \%)\end{array}$ & $\begin{array}{c}-0.0456 \\
(-24.37 \%)\end{array}$ & $\begin{array}{r}0.0000 \\
(0.00 \%)\end{array}$ \\
\hline Decomposition \# 4 & & $\begin{array}{c}0.2327 \\
(124.37 \%)\end{array}$ & $\begin{array}{c}-0.0204 \\
(-10.90 \%)\end{array}$ & $\begin{array}{l}-0.0252 \\
(-13.47 \%)\end{array}$ \\
\hline
\end{tabular}




\begin{tabular}{||l|c|c|c|c||}
\hline & \multicolumn{4}{|c||}{ Women: Westerners-Easterners } \\
\hline Standard Oaxaca & 0.1927 & $\begin{array}{c}0.1419 \\
(73.64 \%)\end{array}$ & $\begin{array}{c}0.0508 \\
(26.36 \%)\end{array}$ & $\begin{array}{c}0.0000 \\
(0.00 \%)\end{array}$ \\
\hline Decomposition \# 1 & & $\begin{array}{c}0.1044 \\
(54.15 \%)\end{array}$ & $\begin{array}{c}-0.0170 \\
(-8.82 \%)\end{array}$ & $\begin{array}{c}0.1054 \\
(54.67 \%)\end{array}$ \\
\hline Decomposition \# 2 & & $\begin{array}{c}0.2763 \\
(143.38 \%)\end{array}$ & $\begin{array}{c}-0.0836 \\
(-43.38 \%)\end{array}$ & $\begin{array}{c}0.0000 \\
(0.00 \%)\end{array}$ \\
\hline Decomposition \# 3 & & $\begin{array}{c}0.2410 \\
(125.06 \%)\end{array}$ & $\begin{array}{c}-0.0483 \\
(-25.06 \%)\end{array}$ & $\begin{array}{c}0.0000 \\
(0.00 \%)\end{array}$ \\
\hline Decomposition \# 4 & & $\begin{array}{c}0.2410 \\
(125.06 \%)\end{array}$ & $\begin{array}{c}-0.0836 \\
(-43.38 \%)\end{array}$ & $\begin{array}{c}0.0353 \\
(18.32 \%)\end{array}$ \\
\hline
\end{tabular}

\section{Legend:}

Decomposition \# 1: $H=Z_{1} ; D=Z_{4} ; \quad$ Selectivity $=Z_{2}+Z_{3}+Z_{5}$

Decomposition \# 2: $H=Z_{1}+Z_{2}+Z_{3} ; \quad D=Z_{4}+Z_{5}$

Decomposition \# 3: $H=Z_{1}+Z_{2} ; \quad D=Z_{3}+Z_{4}+Z_{5}$

Decomposition \# 4: $H=Z_{1}+Z_{2} ; \quad D=Z_{4}+Z_{5} ; \quad$ Selectivity $=Z_{3}$

where:

$$
\begin{aligned}
& Z_{1}=\left(\bar{X}_{m}-\bar{X}_{f}\right)^{\prime} \hat{\beta}_{m} \\
& Z_{2}=\hat{\theta}_{m}\left(\hat{\lambda}_{m}-\hat{\lambda}_{f}^{0}\right) \\
& Z_{3}=\left(\hat{\theta}_{m}-\hat{\theta}_{f}\right) \hat{\lambda}_{f} \\
& Z_{4}=\bar{X}_{f}^{\prime}\left(\hat{\beta}_{m}-\hat{\beta}_{f}\right) \\
& Z_{5}=\hat{\theta}_{m}\left(\hat{\lambda}_{f}^{0}-\hat{\lambda}_{f}\right)
\end{aligned}
$$

